\title{
Hepatic Perfusion Imaging
}

National Cancer Institute

\section{Source}

National Cancer Institute. Hepatic Perfusion Imaging. NCI Thesaurus. Code C150245.

Any imaging procedure designed to assess the state of fluid flow through the liver. 